\title{
$\mathrm{RF} \mathrm{MEMS}$ 소자를 이용한 $\mathrm{MIMO}$ 안테나 설계
}

\section{Design of a MIMO Antenna Using a RF MEMS Element}

\author{
이 원 우·이 병 호 \\ Won-Woo Lee $\cdot$ Byung-Ho Rhee \\ 요 약
}

본 논문에서는 다중 입출력(Multiple-Input Multiple-Output: MIMO) 무선 기계에 대한 안테나의 설계를 제안하 였다. 제안된 안테나는 다양한 LTE(Long Term Evolution) 서비스 대역을 다룬다; 밴드(band) 17(704 746 MHz), 밴드 13(746 787 MHz), 밴드 5(824 894 MHz), and 밴드 8(880 960 MHz). 제안된 주(main) 안테나는 광대역 동작을 위해 역 L-형태의 슬릿(slit)을 가지고 있다. 그리고 LTE 부(sub) 안테나는 스위치(switch)를 결합한 루프 (loop) 안테나 구조에 기초를 두었고, 논리 회로에 의해서 공진 주파수가 조절될 수 있다. LTE 수신 안테나에 대한 조절 기술은 원하는 대역의 실현을 위해, 그리고 임피던스(impedance) 조절을 위해 RF MEMS(Micro-Electro Mechanical System)를 사용하였다. 두 개의 제안된 안테나는 서로 수직으로 편파되기 때문에 원하는 주파수 대역 에서 두 안테나는 $-20 \mathrm{~dB}$ 이하의 격리도 특성을 가지며, 두 안테나 사이의 상관 계수(Envelope Correlation Coefficient: ECC) 특성은 0.06 이하의 매우 낮은 값을 가진다. 제안된 안테나는 통합된 LTE 다중 입출력 시스템의 단말기에 적용이 가능하다.

\section{Abstract}

In this letter, a new approach is proposed for the design of a multi antenna for MIMO wireless devices. The proposed antenna covers various LTE(Long Term Evolution) service bands: band 17(704 746 MHz), band 13(746 $787 \mathrm{MHz})$, band $5(824 \sim 894 \mathrm{MHz})$, and band $8(880 \sim 960 \mathrm{MHz})$. The proposed main antenna consists of a conventional monopole antenna with an inverted L-shaped slit for wideband operation. The proposed the LTE sub antenna is based on a switch loaded loop antenna structure, with a resonance frequency that can be controlled by capacitance of a logic circuit. The tuning technique for the LTE Rx antenna uses a RF MEMS(Micro-Electro mechanical system) to match the impedances to realize the bands of interest. Because the two proposed antennas are polarized orthogonally to each other, the ECC(Envelope Correlation Coefficient) characteristic between two antennas was measured to be very low (below 0.06) with an isolation characteristic below $-20 \mathrm{~dB}$ between the two antennas in the operating overall LTE bands. The proposed antenna is particularly attractive for mobile devices that integrate LTE multiple systems.

Key words : Antenna, ECC, LTE, MIMO, RF MEMS

\section{I. 서 론}

LTE 단말기의 빠른 성장은 다양한 주파수 대역에
서의 동작과 다중 기능의 성능에 대한 요구를 초래 하였다. 단말기에 적용 가능한 안테나들은 다중 대 역 동작 그리고 안테나 사이의 격리도 뿐만 아니라,

한양대학교 전자컴퓨터통신공학과(Department of Electronic \& Computer Engineering, Hanyang University)

- Manuscript received October 23, 2013 ; Revised November 25, 2013 ; Accepted November 26, 2013. (ID No. 20131023-100)

- Corresponding Author : Byung-Ho Rhee (e-mail : bhrhee@hanyang.ac.kr) 
넓은 대역폭, 높은 안테나 이득과 같은 중요한 특성 을 요구하고 있다맘하지만 작은 $\mathrm{MIMO}$ 단말기의 낮은 주파수 대역의 구현에 있어서 공통 접지면의 사용으로 인해 두 안테나간 상호 간섭이 생기며, 이 런 현상은 안테나 성능에 치명적인 문제를 일으킨 다[2],[3].

단말기에 대한 $\mathrm{MIMO}$ 시스템에서 안테나 배열에 관하여 심각한 설계 문제는 단말기의 제한된 유효 공간에 있다. 즉, 서로 근접해 있는 안테나는 상호 간섭을 높이고, 서로 영향을 받는다. 상호 간섭은 또 한 두 안테나 간의 상관 계수를 증가시킨다. 최근 일 부 연구 논문들은 안테나 간섭을 줄이는 연구가 활 발히 진행되고 있다 ${ }^{[4] ~[7]}$. 낮은 주파수 대역에서 접 지(ground) 면에 전류를 제한하기 위해 메타물질(metamaterials)을 사용하여 높은 간섭을 줄였고 ${ }^{[4]}$, 두 안 테나 사이에서 정합회로를 구현하여 이런 문제를 해 결하기 위한 기술 ${ }^{[5]}$, 접지면의 공진을 이용 ${ }^{[6]}$, 그리고 갈라진 고리 공진을 이용한 기술이 ${ }^{[7]}$ 연구되었다. 위 에서 언급한 기술들은 모두 반사계수를 저하시키며, 높은 격리를 가지면서 동시에 넓은 임피던스 대역폭 을 이루긴 어렵다. 또한, 이러한 기술들은 부가적인 공간이 필요하다.

이 논문에서는 주 안테나의 경우 넓은 대역 동작 을 달성하기 위해서 주 안테나는 역 L-형태의 슬릿 을 가지는 모노폴(monopole) 안테나가 제안되었다. LTE 수신부의 부 안테나는 다중의 공진을 가지며, 동작 대역은 LTE 수신 루프 안테나의 끝에 연결된 $\mathrm{RF}$ MEMS의 캐패시턴스(Capacitance)에 의해서 조절 된다. 주 그리고 부 안테나에 설계된 모노폴과 루프 안테나의 서로 다른 형태는 높은 격리도를 이룬다.

\section{II. 안테나 구조}

\section{2-1 주 안테나 설계}

제안된 안테나 설계에서 주(송신+수신) 안테나와 부(수신) 안테나는 그림 1에서 보는 바와 같이 각각 접지면의 하단과 상단 왼쪽에 위치하였다. 접지 평 면의 크기는 $60 \mathrm{~mm} \times 120 \mathrm{~mm}$ 이고, 두께 $0.8 \mathrm{~mm}$, 상 대 유전율 4.4를 가지는 FR4 기판을 사용하였다.

주 안테나의 전체 크기는 $10 \mathrm{~mm} \times 60 \mathrm{~mm} \times 6 \mathrm{~mm}$ 이 며, 이것은 특정 단말기에 있어 적합한 크기이다. 제

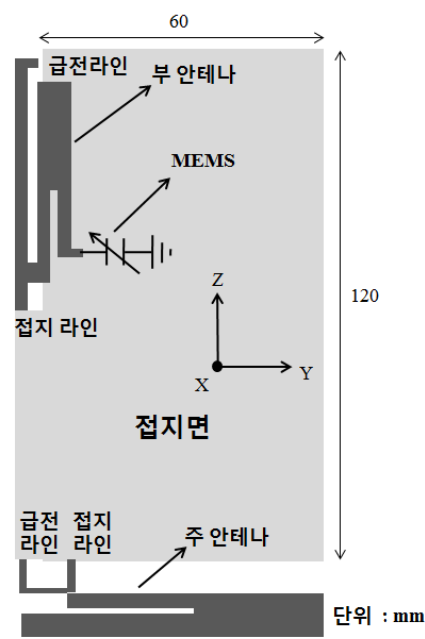

그림 1. 제안된 MIMO 안테나의 구조

Fig. 1. The structures of the proposed MIMO antenna.

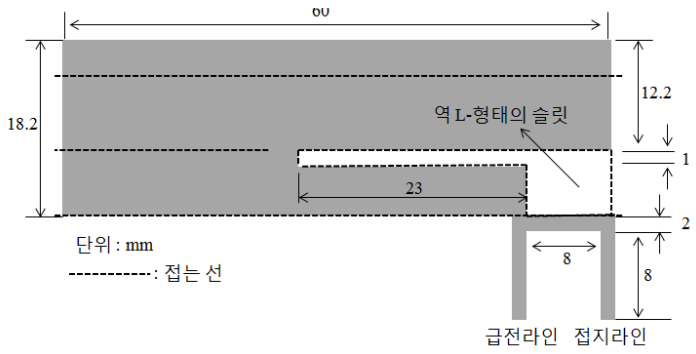

그림 2. 제안된 주 안테나의 구조 및 크기

Fig. 2. Detailed structure and dimension of the proposed main antenna.

안된 주 안테나는 그림 2와 같이 사각형의 방사 요 소와 넓은 대역 성능을 이루기 위해 역 L-형태의 슬 릿으로 구성하였다.

제안된 주 안테나의 변수들을 CSTs Microwave $\mathrm{Studio}^{[8]}$ 시뮬레이션을 통해 최적화 하였다. 그림 3은 역 L-형태의 슬릿의 유무에 따른 시뮬레이션 결과 및 측정값을 보여준다. 역 L-형태의 슬릿을 적용함 으로써 공진 주파수의 저주파로의 이동 및 동일 안 테나 크기에서 광대역 특성을 구현할 수 있다. 또한, 제안된 주 안테나의 측정된 반사 손실 $\left(S_{11}\right)$ 특성은 시뮬레이션 값과 유사하다.

이 그림으로부터 역 L-형태의 슬릿을 가지고 있 는 제안된 안테나의 공진 주파수는 역 L-형태의 슬 릿을 가지고 있지 않는 안테나보다 낮은 주파수 대 역으로 이동하고, 임피던스 대역폭이 $27.8 \%$ 에서 


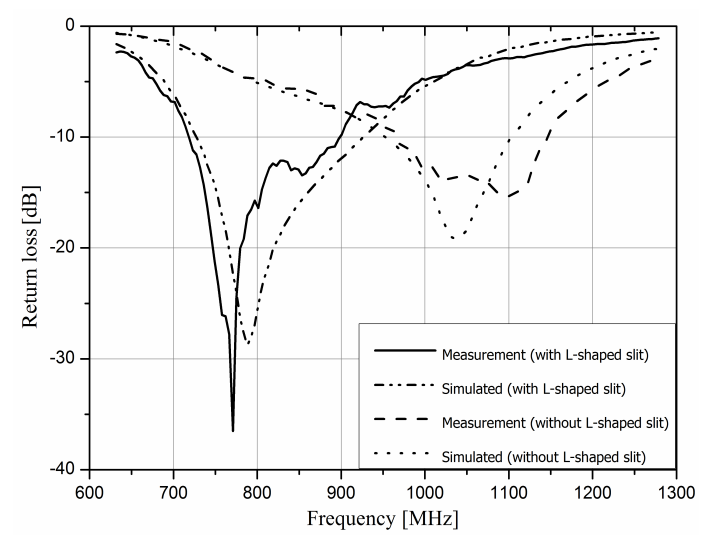

그림 3. 제안된 주 안테나에 대한 시뮬레이션 및 측정 반사 손실 특성

Fig. 3. Simulated and measured return loss characteristics for the proposed main antenna.

$34.4 \%$ 로 개선됨을 알 수 있다. 또한, $6 \mathrm{~dB}$ 반사 손실 요구 기준으로 $688 \sim 974 \mathrm{MHz}$ 의 다양한 LTE 주파수 (LTE 밴드 17, 13, 5, 그리고 8)에서 동작할 수 있는 광대역 특성을 얻었다.

\section{2-2 부 안테나 설계}

그림 4는 LTE 수신부의 부 안테나인 접은 미엔더 (folded meander) 루프 안테나의 구성을 보여준다. 루 프 안테나는 두 안테나 사이에서 안테나 위치에 따 라 높은 격리도 특성을 가질 수 있다 ${ }^{[9]}$. LTE 수신 안 테나는 낮은 LTE 대역 동작에 대해서 단순한 구성 을 가진다. 원하는 LTE 서비스 대역으로의 특성 변 화를 위해서 MEMS 캐패시터는 미엔더 루프 안테나 의 끝에 연결하였다.

제안된 RF MEMS 캐패시터는 Cavendish Kinetics

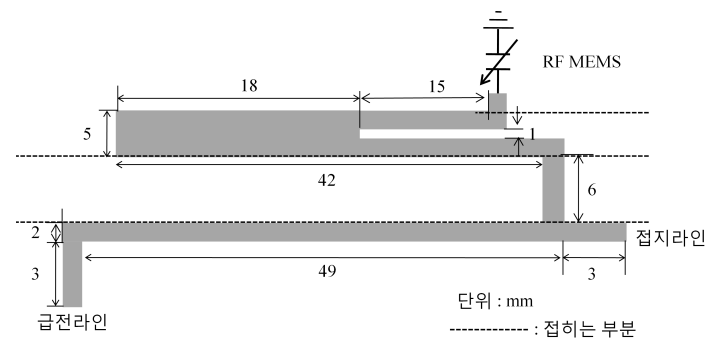

그림 4. 제안된 부 안테나의 구조 및 크기

Fig. 4. Detailed structure and dimension of the proposed sub antenna.

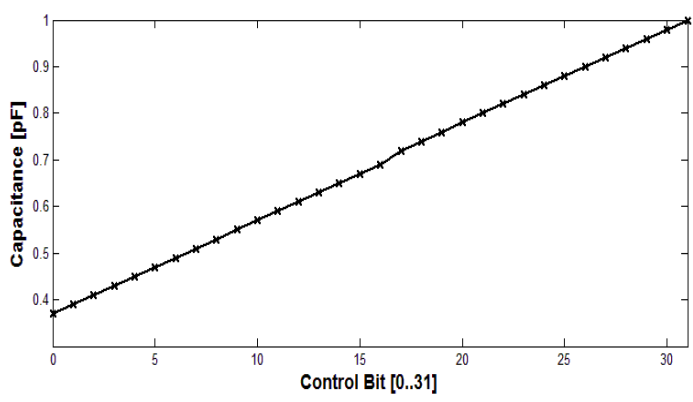

그림 5. 구성된 단계 크기에 대한 제안된 MEMS 캐 패시터의 특성

Fig. 5. Performance of proposed MEMS capacitor for consistent step size.

사의 $32 \mathrm{CK} 301^{[10]}$ 를 사용하였다. MEMS 캐패시터는 다른 재질의 캐패시터에 비해서 저항 성분이 낮아 안테나 적용 시 손실이 적다. 그림 5 에서 보는 것처 럼 논리 상태(Logic State) 0 bit에서 31 bit까지 조절 되어 캐패시턴스는 약 $0.03 \mathrm{pF}$ 단계로 $0.37 \mathrm{pF}$ 에서 1 $\mathrm{pF}$ 까지 변함을 볼 수 있다. 이런 캐패시턴스의 특성 변화는 본 논문에서 설계된 LTE 부 안테나의 매칭 값의 범위에 들며, 이 값을 통해 LTE 4개 밴드를 선 택할 수 있다.

그림 6은 다양한 캐패시턴스를 가지는 제안된 LTE 수신부의 부 안테나의 반사 손실 측정값을 보 여준다. 캐패시턴스 값에 따라서 4개의 수신 대역이 선택된다. 4개의 LTE 밴드를 선택하기 위한 다른 부 수적인 매칭단(Matching network)은 필요하지 않는 다. 이것은 넓은 주파수 대역을 조절하는 캐패시턴 스 값이 변하는 동안 우수한 임피던스 매칭이 된다 는 점에서 중요성을 둘 수 있다. 제안된 LTE 수신 안테나는 캐패시턴스 값을 통해서 연속적으로 원하 는 서비스 밴드를 선택할 수 있다. 밴드 17 과 13 의 경우, $1 \mathrm{pF}, 0.96 \mathrm{pF}$ 의 각각 하나의 값으로 밴드 대역 폭을 포함시킬 수 있으나, 밴드 5와 8의 경우 0.5 $0.53 \mathrm{pF}, 0.34 \sim 0.37 \mathrm{pF}$ 의 범위로 각각 대역폭을 포함 시킬 수 있다. 이렇게 한 가지 캐패시턴스로 특정 밴 드의 대역폭을 포함하지 못할 경우에는 단말기 모뎀 에서 특정 밴드에 속하는 주파수 채널을 조절함으로 써 해결할 수 있다. LTE 수신 대역이 LTE 수신 안테 나의 캐패시턴스 값의 의해서 조절되며, 주 안테나 의 공진은 크게 영향을 받지 않는다. 


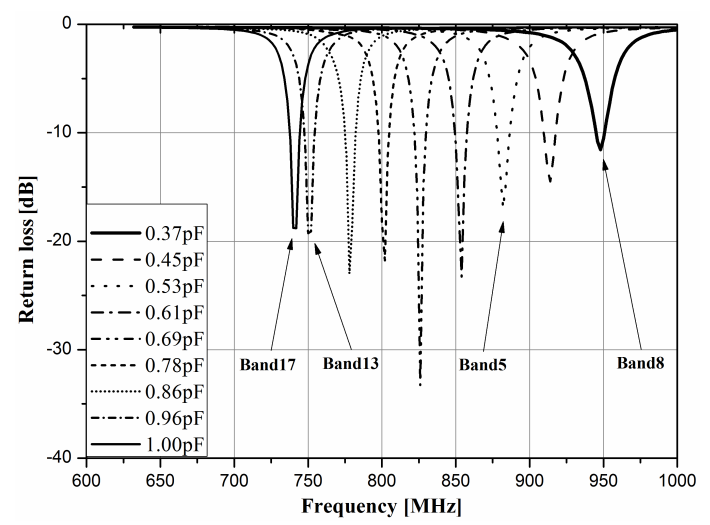

그림 6. 제안된 부 안테나에 대한 측정된 반사 손 실 특성

Fig. 6. Measured return loss characteristics for the proposed sub antenna.

\section{MIMO 성능}

그림 7은 4개의 LTE 서비스 밴드에서 두 안테나 사이의 산란 파라미터(S-parameter) 특성을 측정했다. 그림에서 보는 것처럼 $-20 \mathrm{~dB}$ 이상의 격리도 특성 을 가진다. 이러한 서로 간섭의 수준은 낮은 주파수 대역에서 최근 발표되는 논문들보다 더 우수함을 알 수 있다 ${ }^{[1],[12] .}$

그림 8은 LTE 낮은 주파수의 수신 대역에서 밴드 17 과 밴드 8 에 대한 안테나의 접지면에 대한 표면 전류 분포에 대한 시뮬레이션 결과를 각각 보여준 다. 전류 분포는 보고자 하는 안테나에 급전시켰고,

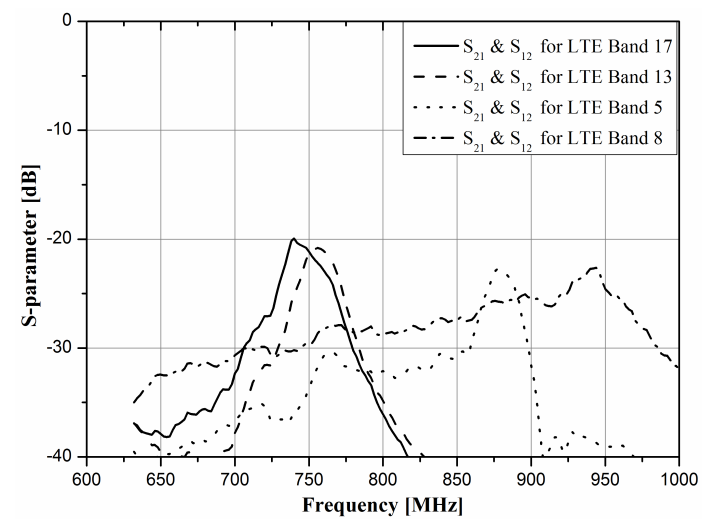

그림 7. LTE 밴드에 대한 측정된 $S_{21}$ 그리고 $S_{12}$ 특성

Fig. 7. Measured $S_{21}$ and $S_{12}$ characteristics for LTE band. (a)

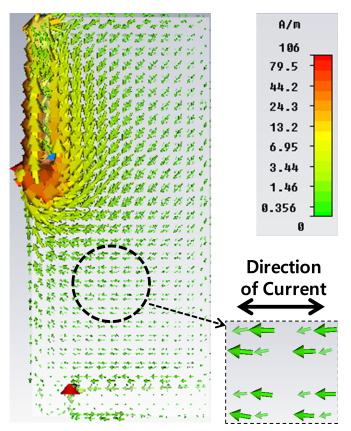

(c)

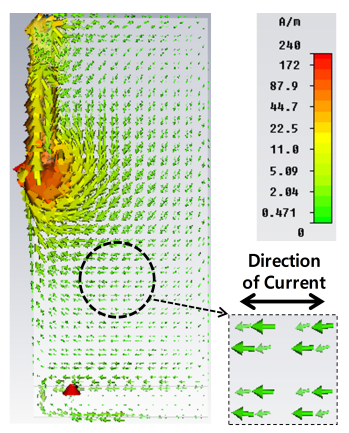

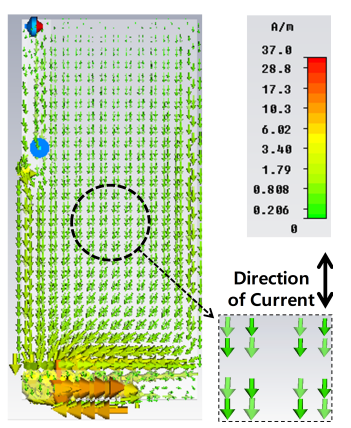

(b)

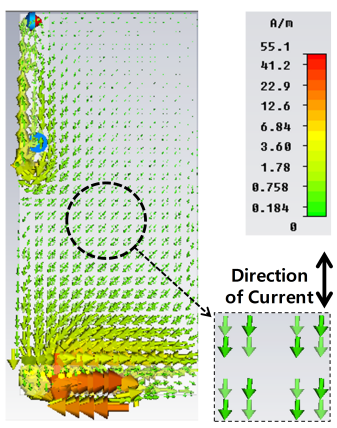

(d)
그림 8. (a) 밴드 17에 대한 부 안테나의 표면 전류 분포, (b) 밴드 17에 대한 주 안테나의 표 면 전류 분포, (c) 밴드 8에 대한 부 안테 나의 표면 전류 분포, (d) 밴드 8 에 대한 주 안테나의 표면 전류 분포

Fig. 8. (a) Surface current distribution of sub antenna for band 17, (b) Surface current distribution of main antenna for band 17, (c) Surface current distribution of sub antenna for band 8, (d) Surface current distribution of main antenna for band 8 .

다른 하나는 $50 \Omega$ 으로 연결하였다. 제안된 안테나 설계에서 LTE 수신단의 부 안테나에 대한 표면 전 류 분포는 거의 수평으로 형성되는 반면에, 주 안테 나의 경우 수직으로 형성됨을 알 수 있다. 결국, 두 안테나의 전류 분포는 서로 수직적인 특성을 가지고 있으며, 이를 통해 격리도 특성이 개선될 수 있는 구 조임을 확인할 수 있다.

그림 9에서 보는 바와 같이 주 안테나에서 측정된 평균 이득은 $-0.22 \mathrm{dBi}$ 에서 $-1.67 \mathrm{dBi}$ 이며, 이득 변 화량은 $1.45 \mathrm{~dB}$ 이다. LTE 수신의 부 안테나의 평균 이득은 $-1.57 \mathrm{dBi}$ 에서 $-4.61 \mathrm{dBi}$ 이며, 이득 변화량 은 $3.04 \mathrm{~dB}$ 를 가진다. 모든 동작 대역에 대해서 실질 


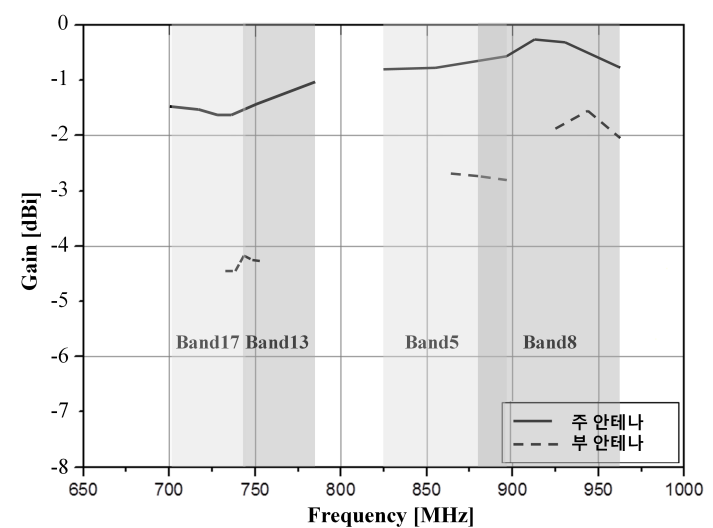

그림 9. 측정된 평균 이득

Fig. 9. Measured average gain

적인 단말기와 비교해 볼 때 안테나 효율은 적절한 편이다.

그림 10 과 11 은 자유 공간에서 주 안테나와 부 안 테나의 측정된 방사 패턴들을 보여준다. 아래 그림 의 이득 및 방사 패턴은 두 개의 안테나 중 하나는 50 옴으로 터미네이션 시킨 상태에서 측정하였다.

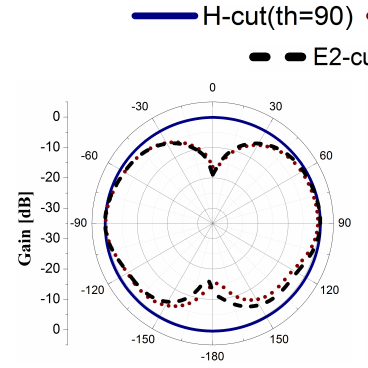

(a) 밴드 17

(a) Band 17

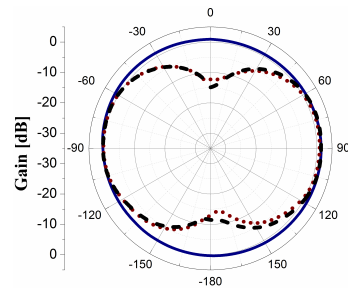

(c) 밴드 5

(c) Band 5

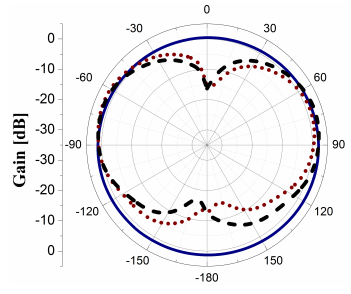

(d) 밴드 8
그림 10. 다양한 LTE 대역에서 주 안테나의 측정 된 방사 패턴들

Fig. 10. Measured radiation patterns for the main antenna in various LTE bands.

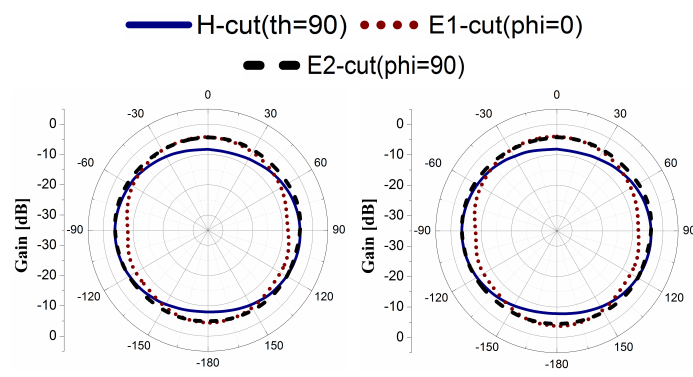

(a) 밴드 17

(b) 밴드 13

(a) Band 17

(b) Band 13

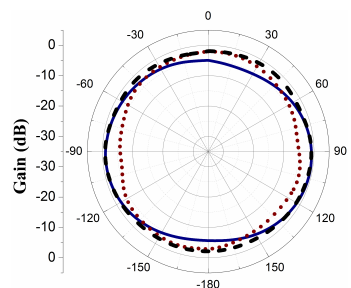

(c) 밴드 5

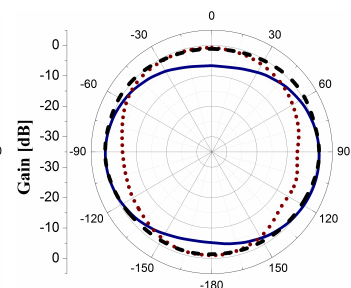

(d) 밴드 8

(d) Band 8
그림 11. 다양한 LTE 대역에서 부 안테나의 측정된 방사 패턴들

Fig. 11. Measured radiation patterns for the sub antenna in various LTE bands.

$\mathrm{MIMO}$ 안테나 설계가 일반적으로 각 안테나에 대해 서 다른 방향성을 가진다고 할지라도 제안한 안테나 의 방사 패턴은 서로 비슷하다. $\mathrm{H}(\mathrm{yz})$ 평면은 동작 대역에서 거의 전방향(omnidirectional)의 패턴임을 볼 수 있다.

$\mathrm{MIMO}$ 안테나로서 제안된 안테나 구조의 시스템 성능을 검증하기 위해서 상관 계수를 계산하였다. $\mathrm{MIMO}$ 안테나를 적용한 상업 목적의 단말기에서 안 테나의 상관 관계는 본질적으로 높다. 왜냐하면 서 로 근접해 있는 두 안테나는 강하게 간섭되기 때문 이다. 이 문제는 같은 접지를 공유하는 MIMO 안테 나에 대해서 전기적으로 긴 파장을 사용하는 낮은 주파수의 LTE 대역에서 특히 악화된다. 일반적인 MIMO 성능에 대해서 받아들일 수 있는 상관 계수 는 0.5 이하로 보고되고 있다 ${ }^{[13]}$. 균일한 다중 경로 환경의 가정 하에서 살펴볼 때, 안테나 방사 패턴의 측정으로부터 두 안테나 시스템의 상관 계수 계산은 유도된다. 이 상관 관계는 식 (1)로 부터 구할 수 있 다 ${ }^{[1]}$. 
표 1. 측정된 상관 계수 특성

Table 1. Measured ECC characteristics.

\begin{tabular}{|c|c|c|}
\hline 서비스 밴드 & $\begin{array}{c}\text { 주파수 } \\
{[\mathrm{MHz}]}\end{array}$ & $\begin{array}{c}\text { 방사 패턴으로 } \\
\text { 부터의 상관 계수 }\end{array}$ \\
\hline LTE band 17 & 740 & 0.05 \\
\hline LTE band 13 & 751 & 0.03 \\
\hline LTE band 5 & 881 & 0.06 \\
\hline LTE band 8 & 942 & 0.03 \\
\hline
\end{tabular}

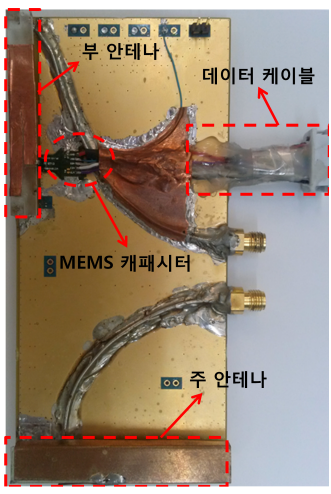

(a) 앞

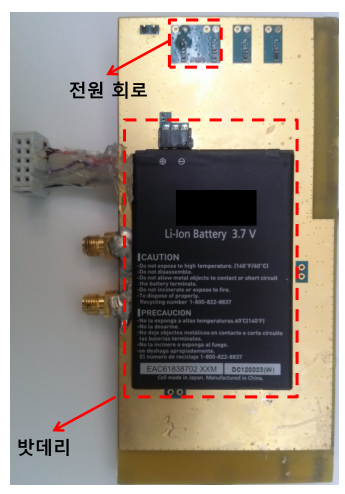

(b) 뒤

(b) Bottom

그림 12. 제작된 안테나

Fig. 12. The fabricated antenna.

$\rho_{12}=$

$\frac{\left|\oint\left\{X P R \cdot E_{\theta M A}(\Omega) \cdot E_{\theta S A}^{*}(\Omega)+E_{\phi M A}(\Omega) \cdot E_{\phi S A}^{*}(\Omega)\right\} d \Omega\right|^{2}}{\oint\left\{X P R \cdot G_{\theta M A}(\Omega)+G_{\phi, M A}(\Omega)\right\} d \Omega \cdot \oint\left\{X P R \cdot G_{\theta S A}(\Omega)+G_{\phi S A}(\Omega)\right\} d \Omega}$

$E_{\theta M A}(\Omega)$ 는 주 안테나의 수직 편파 복소수의 방사 패턴이고, $E_{\theta S A}(\Omega)$ 는 부 안테나의 수직 편파 복소수 의 방사 패턴이다. $E_{\varnothing M A}(\Omega)$ 는 주 안테나의 수평 편파 복소수의 방사 패턴이고, $E_{\varnothing S A}(\Omega)$ 는 부 안테나의 수 평 편파 복소수의 방사 패턴이다. $\Omega$ 은 구 좌표계 시 스템에 대한 입체각이다. 여기서 측정 환경이 등방 성(isotropic)이기 때문에 $X P R=1$ 이다. $X P R$ 은 교차 편 파비를 나타낸다 ${ }^{[15]}$. 즉, 수직 편파와 수평 편파의 비 를 동일하게 함으로써, 균일한 Rayleigh 환경에서 안 테나의 특성을 보기 위함이다. 표 1은 방사 패턴으 로부터 측정된 상관 계수를 정리하였다. 그 상관 계 수 특성은 LTE 대역 $17,13,5$, 그리고 8 에서 0.06 이 하로 측정되었다. 상관 계수가 낮다는 결과는 그림 7 에서 설명된 산란 파라미터의 결과로부터도 유추

할 수 있다. 이것은 제안된 안테나는 상관 계수 저하 됨을 알 수 있으며, 최근 연구된 논문들 보다 낮은 특성을 가진다 ${ }^{[12],[16]}$.

그림 12 는 제작된 안테나를 보여준다. 제안된 안 테나와 MEMS 캐패시터는 $\mathrm{PCB}$ 의 앞면에, 그리고 5 $\mathrm{V}$ 직류 밧데리와 전원 회로는 $\mathrm{PCB}$ 의 뒷면에 제작 되었다. 여기서 전원 회로는 MEMS 캐패시터에 2.6 $\mathrm{V}$ 를 공급하기 위해 $\mathrm{LDO}(\mathrm{Low}$ Drop Out) 조정기를 사용하였다.

\section{IV. 결 론}

제안된 $\mathrm{MIMO}$ 주 안테나는 넓은 대역폭을 가지고 있으며, 4 개의 LTE 대역에서 동작한다. 이것은 광대 역 특성을 구현하기 위해 역 L-형태의 슬릿을 구현 하였다. LTE 수신부의 부 안테나에 대해서 다중 대 역 특성은 RF MEMS에 의해서 이루어진다. 그 동작 대역은 MEMS의 캐패시턴스를 조절함으로써 선택 될 수 있다. 주 안테나와 부 안테나(모노폴과 루프 안테나)는 다른 안테나 형태를 선택함으로써 매우 우수한 격리도 특성뿐만 아니라, 상관 계수 특성을 얻을 수 있었다. 제안된 설계는 LTE 낮은 주파수 대 역의 $\mathrm{MIMO}$ 동작에서 매우 유용하게 사용될 수 있 을 것이다.

\section{References}

[1] Z. Ying, D. Zhang, "Study of the mutual coupling, correlations and efficiency of two PIFA antennas on a small ground plane", in Proc. IEEE Antennas Propagat. Soc. Int. Symp., pp. 305-308, Jul. 2005.

[2] S. Blanch, J. Romeu, and I. Corbella, "Exact representation of antenna system diversity performance from input parameter description", IET Electron. Lett., vol. 39, no. 9, pp. 705-707, May 2003.

[3] F. G. Zhu, J. D. Xu, and Q. Xu, "Reduction of mutual coupling between closely-packed antenna elements using defected ground structure", IET Electron. Lett., vol. 45, no. 12, pp. 601-602, Jul. 2009.

[4] N. Lopez, C. Lee, A. Gummalla, and M. Achour, "Compact metamaterial antenna array for Long Term Evolution(LTE) handset application", Antenna Te- 
chnology, iWAT 2009, IEEE International Workshop on, pp. 1-4, Mar. 2009.

[5] 한민석, 최재훈, "대역 저지 특성을 갖는 정합 회 로를 이용한 USB dongle용 이중 대역 MIMO 안 테나" 한국전자파학회논문지, 20(9), pp. 924-929, 2009년 9월.

[6] Xing Zhao, Kyeol Kwon, and Jeahoon Choi, "MIMO antenna using resonance of ground plane for 4G mobile application", J. Electromagn. Eng. Sci., vol. 13, no. 1, pp. 51-53, Mar. 2013.

[7] Youngki Lee, Haeil Chung, and Jaehoon Choi, "Improving the isolation of MIMO antennas using split ring resonators", J. Electromagn. Eng. Sci., vol. 10, no. 4, pp. 303-308, Dec. 2010.

[8] Computer Simulation Technology(CST) Microwave Studio Suite 2012 [Online] Available: http://www. cst.com

[9] 염인수, 정창원, "소형 고 격리도 듀얼 밴드 MI$\mathrm{MO}$ 안테나" 한국전자파학회논문지, 21(8), pp. 865871, 2010년 8월.

[10] http://www.cavendish-kinetics.com

[11] M. S. Sharawi, S. S. Iqbal, and T. S. Faouri, "An

이 원 우

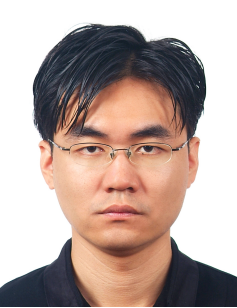

2000년 2월: 광운대학교 전자물리 학과 (이학사)

2002년 2월: 광운대학교 전파공학 과 (공학석사)

2007년 3월 현재: 한양대학교 전자 컴퓨터통신공학과 박사과정 2002년 2003년: (주)텔슨전자 연구

원

2004년 2006년: (주)SK텔레텍 주임연구원

2007년 현재: (주)LG전자 책임연구원

[주 관심분야] LTE 시스템, MIMO, 안테나 및 마이크로파 회로 설계
$800 \mathrm{MHz} 2 \times 1$ compact MIMO antenna system for LTE handsets", IEEE Trans. Antennas Propag., vol. 59, no. 8, pp. 3128-3131, Aug. 2011.

[12] J. Chung, T. Yang, J. Lee, and J. Jeong, "Low correlation MIMO antenna for LTE $700 \mathrm{MHz}$ band", in Proc. IEEE Antennas Propagat. Soc. Int. Symp., pp. 2202-2204, Jul. 2011.

[13] R. G. Vaughan, J. B. Andersen, "Antenna diversity in mobile communications", IEEE Trans. Veh. Technol., vol. 36, no. 4, pp. 149-172, Nov. 1987.

[14] I. Szimi, G. F. Pedersen, S. C. Del Barrio, and M. D. Foegelle, "LTE radiated data throughput measurements, adopting MIMO 2×2 reference antennas", IEEE Vehicular Technology Conference(VTC Fall), VTC, pp. 1-5, 2012.

[15] 김성진, 김동호, 권결, 최재훈, "인체부착형 Headset $\mathrm{MIMO}$ 안테나 설계" 한국전자파학회논문지, 22(12), pp. 1107-1115, 2011년 12월.

[16] R. Kuonanoja, "Low correlation handset antenna configuration for LTE MIMO applications", in $\mathrm{Pr}$ oc. IEEE Antennas Propagat. Soc. Int. Symp., pp. 1-4, Jul. 2010.
이 병 호

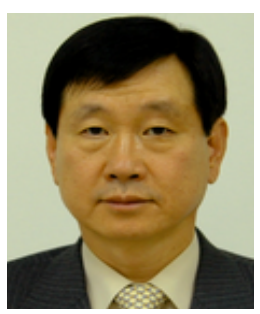

1975년 2월: 한양대학교 전자공학 과 (공학사)

1977년 2월: 한양대학교 전자공학 과 (공학석사)

1993년 3월: National Chiba University (공학박사)

1981년 현재: 한양대학교 컴퓨터공

학부 교수

[주 관심분야] 네트워크, NGN, 무선망 보안, 무선 통신 